\title{
Aegle marmelos Mediated Green Synthesis of Different Nanostructured Metal Hexacyanoferrates: Activity against Photodegradation of Harmful Organic Dyes
}

\author{
Vidhisha Jassal, Uma Shanker, and B. S. Kaith \\ Department of Chemistry, Dr. B. R. Ambedkar National Institute of Technology, Jalandhar, Punjab 144011, India \\ Correspondence should be addressed to Uma Shanker; umaorganic29@gmail.com
}

Received 10 December 2015; Accepted 26 January 2016

Academic Editor: Zhen Cheng

Copyright (C) 2016 Vidhisha Jassal et al. This is an open access article distributed under the Creative Commons Attribution License, which permits unrestricted use, distribution, and reproduction in any medium, provided the original work is properly cited.

\begin{abstract}
Prussian blue analogue potassium metal hexacyanoferrate (KMHCF) nanoparticles $\mathrm{Fe}_{4}\left[\mathrm{Fe}(\mathrm{CN})_{6}\right]_{3}(\mathrm{FeHCF}), \mathrm{K}_{2} \mathrm{Cu} 3\left[\mathrm{Fe}(\mathrm{CN})_{6}\right]_{2}$ (KCuHCF), $\mathrm{K}_{2} \mathrm{Ni}\left[\mathrm{Fe}(\mathrm{CN})_{6}\right] \cdot 3 \mathrm{H}_{2} \mathrm{O}(\mathrm{KNiHCF})$, and $\mathrm{K}_{2} \mathrm{Co}\left[\mathrm{Fe}(\mathrm{CN})_{6}\right](\mathrm{KCoHCF})$ have been synthesized using plant based biosurfactant Aegle marmelos (Bael) and water as a green solvent. It must be emphasized here that no harmful reagent or solvent was used throughout the study. Plant extracts are easily biodegradable and therefore do not cause any harm to the environment. Hence, the proposed method of synthesis of various KMHCF nanoparticles followed a green path. The synthesized nanoparticles were characterized by powder X-ray diffraction (PXRD), Field-Emission Scanning Electron Microscopy (FE-SEM), Transmission Electron Microscopy (TEM), and Fourier Transform Infrared Spectroscopy (FT-IR). MHCF nanoparticles were used for the photocatalytic degradation of toxic dyes like Malachite Green (MG), Eriochrome Black T (EBT), Methyl Orange (MO), and Methylene Blue (MB). Under optimized reaction conditions, maximum photocatalytic degradation was achieved in case of KCuHCF nanoparticles mediated degradation process (MG: 96.06\%, EBT: 83.03\%, MB: 94.72\%, and MO: 63.71\%) followed by KNiHCF (MG: 95\%, EBT: 80.32\%, MB: 91.35\%, and MO: 59.42\%), KCoHCF (MG: 91.45\%, EBT: 78.84\%, MB: 89.28\%, and MO: $58.20 \%)$.
\end{abstract}

\section{Introduction}

In last few years, Prussian Blue (PB) and its analogues have gained worldwide attraction because of the presence of unique properties like electrochromic, electrochemical, and magnetic properties [1]. Metal hexacyanoferrates are generally denoted with the general formula $\mathrm{M}_{k}\left[\mathrm{Fe}(\mathrm{CN})_{6}\right] \cdot x \mathrm{H}_{2} \mathrm{O}$ where $\mathrm{M}$ is a transition metal in the high spin and $\mathrm{Fe}$ in the low spin configuration. Properties of such complexes have been found to change with the replacement of outer coordination sphere transition metal with another. Metal-tometal charge transfer between the two transition metal ions exhibits the redox behavior. Catala et al. reported that nano range $\mathrm{PB}$ analogues show unique characteristics as compared to their bulk form; for example, nickel hexacyanoferrate nanoparticles possessed super-paramagnetic property [2]. Effect of nanosize in magnetic phase transition temperature with $\mathrm{PB}$ nanoparticles was found $[3,4]$ and owing to such outstanding properties these nanostructures can be applied in various fields like electrochemistry [5-7], optics [8] and molecular magnets [9-12], and battery electrode materials [13-15].

PB analogues can be synthesized using various techniques such as sol-gel or using surfactants like cetyltrimethyl ammonium bromide (CTAB), ethylene diaminetetraacetate (EDTA) or polymers such as poly(vinylpyrrolidone), or in presence of mesostructured silica, porous alumina, and nafion [16-18].

Currently, the use of green nanotechnology is growing worldwide as it involves wide variety of pathways that eliminate the use of toxic substances in order to restore the environment. One of the potential promising methods for the synthesis of nanoparticles employs use of multifunctional nontoxic reactants derived from various parts of plants, such as plant extracts [19], tissues [20], exudates [21], and other parts of the living plants [22]. These parts of the plants are 
<smiles>COc1ccc2c(OC)c3ccoc3nc2c1OC</smiles>

Skimmianine<smiles>COc1c2ccoc2nc2c(OC)cccc12</smiles>

Fagarine<smiles>COc1ccc([C@@H](O)CNC(=O)/C=C/c2ccccc2)cc1</smiles>

Aegelin<smiles>CC(C)=CCOc1ccc(/C=C/NC(=O)/C=C/c2ccccc2)cc1</smiles>

Anhydromarmelin<smiles>COC1=CCC(C(O)CNC(=O)C=Cc2ccccc2)C=C1</smiles>

Aegelin<smiles>C=C(C)[C@H]1CCC2(C)CC[C@@H]3[C@](C)(CC[C@@H]4[C@@]5(C)CC[C@H](O)[C@@H](C)[C@@H]5CC[C@]34C)[C@H]12</smiles>

Lupeol<smiles>CC(C)c1ccc(C=O)cc1</smiles>

4-Isopropylbenzaldehyde<smiles>C=CCc1ccc(O)c(OC)c1</smiles>

Eugenol<smiles>CC(C)=CCC/C(C)=C/C=O</smiles>

Citral<smiles>CC(C)=CCOc1c2occc2cc2ccc(=O)oc12</smiles>

Marmelide<smiles>CC(C)=CCCC(C)CC=O</smiles><smiles>C/C(=C\COc1ccc2ccc(=O)oc2c1)CC[C@@H](O)C(C)(C)O</smiles>

Marmin<smiles>CC(C)=CCC/C(C)=C/COc1ccc2ccc(=O)oc2c1</smiles>

Aurapten

FIGURE 1: Structures of various bioactive compounds present in Aegle marmelos [40].

easily available and do not harm the tree itself. Moreover, storage of these parts of plants is very easy. Hence, plant based green protocols are hazard-free, environmentally safer, simple, and fast [23].

The use of such biomaterials for the formation of nanoscale inorganic substances is an alternative to the chemical methods [24]. Various scientists worldwide have carried out research in this new emerging field of nanochemistry and they have successfully synthesized nanoparticles using biogenic source. For example, Gardea-Torresdey et al. reported for the first time synthesis of gold nanoparticles inside live alfalfa plant [25]. Similarly, the same group in 2003 demonstrated the use of alfalfa sprouts for the synthesis of silver nanoparticles [26].

Recently, Ahmed et al. applied a simple and rapid approach for the synthesis of silver nanoparticles using Azadirachta indica aqueous leaf extract [27]. Biosynthesis of nanoparticles using different plant species like Aloe vera
[28], Cinnamomum camphora [29], Capsicum annuum L. [30], Medicago sativa and Brassica juncea [31], Brassica chicory [32], Azadiracta indica [33] and Cymbopogon flexuous [34], Ficus Microcarpa [35], Clitoria ternatea and Solanum nigrum [36], Prosopis farcta [37], and Dalbergia spinosa [38] has been successfully carried out in the last few decades.

The present research reports on the use of Aegle marmelos (Bael) leaf extract as a natural plant extract for the synthesis of various metal hexacyanoferrate (KMHCF) nanoparticles. Aegle marmelos is known from prehistoric times for its diverse importance in several fields such as medicinal, commercial, nutritional, and environmental [39]. The leaves of this tree mainly contain polyphenols such as alkaloids, terpenoids, and phenylpropanoids (Figure 1) [40]. These leaves are found to be well recognized for their healing power against wide variety of bacterial and fungal infections [39, 41]. Recently, Rao and Paria reported one-pot synthesis of silver nanoparticles of average size $\sim 60 \mathrm{~nm}$ using Aegle marmelos leaf extract 
[42]. The same group used Aegle marmelos leaf extract for the synthesis of $\mathrm{Au}$ and $\mathrm{Ag}$ nanoparticles by optimising process parameters using Taguchi method [43]. Furthermore, Kumar et al. carried out a facile precipitation route for the green synthesis of zinc oxysulfide quantum dots using Aegle marmelos fruit extract [44]. This eco-friendly approach encouraged the authors to use Aegle marmelos as a biosurfactant for the synthesis of different KMHCF nanoparticles.

The rapid pace of industrialisation and its toxic releases into the water effluents have strongly impacted the balance of nature. This makes waste water treatment an important issue. In developing countries, industries are a major source for an economic boost. Dyes play an important role in various industries such as printing, paper, textile, printing, and cosmetics. For processing $1000 \mathrm{~kg}$ of clothes, approximately $1000 \mathrm{~L}$ of water is required. Their discharge into the water bodies without any treatment causes direct threat to the ecosystem. In search of a friendly method, we carried out the successful removal of harmful organic dyes from waste water. In this study, plant-derived natural surfactant, Aegle marmelos, was used for the synthesis of various KMHCF nanoparticles. Activity of the synthesized KMHCF nanoparticles was evaluated for the photocatalytic degradation of harmful organic dyes namely, Malachite Green (MG), Eriochrome Black T (EBT), Methyl Orange (MO), and Methylene Blue (MB).

\section{Material and Methods}

2.1. Chemicals. Potassium ferrocyanide, metal salts, and dyes Eriochrome Black T, Malachite Green, Methyl Orange, and Methylene Blue were purchased from Merck, India, Ltd. Deionized water was used throughout the experiment. Aegle marmelos was collected from Jalandhar (Punjab) India.

2.2. Preparation of Plant Extract. Bael leaves were collected from NIT Jalandhar campus. They were thoroughly washed thrice with deionized water and dried in oven for 48 hours at $40-50^{\circ} \mathrm{C}$. Then, they were crushed into fine powder using grinder. An intense green colored extract of bael was obtained which was used in the present study.

2.3. Synthesis of Potassium Metal Hexacyanoferrate Nanoparticles. Here, we report the green synthesis of potassium metal hexacyanoferrate nanoparticles using Aegle marmelos as a biosurfactant. $100 \mathrm{~mL}$ of $0.1 \mathrm{M}$ potassium ferrocyanide was slowly added to $100 \mathrm{~mL}$ of $0.1 \mathrm{M}$ respective metal salts containing small amount of Aegle marmelos as a natural surfactant. Excess metal salt was used to get the maximum precipitation and the reaction mixture was kept undisturbed for 24 hours at ambient temperature. The precipitates were filtered and washed thoroughly with water and dried in hot air oven at $60^{\circ} \mathrm{C}$. The dried product was ground and sieved with 100 mesh size sieve.

\subsection{Characterization of KMHCF Nanoparticles}

2.4.1. Field-Emission Scanning Electron Microscopy (FE-SEM). Field-Emission Scanning Electron Microscopy (FE-SEM) was performed in order to find out the surface morphology and average particle size of the synthesized KMHCF nanoparticles (Quanta 200 FEG).

2.4.2. X-Ray Diffraction Analysis (XRD). X-ray diffraction (XRD) was recorded on a PAN analytical X-PRT PRO

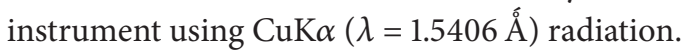

2.4.3. Transmission Electron Microscopy (TEM). Transmission Electron Microscopy (TEM) was conducted with Hitachi $(\mathrm{H}-7500)$ instrument operating at $120 \mathrm{kV}$. This study was carried out in order to find out the exact particle shape and size of the nanoparticles synthesized.

2.4.4. Fourier Transform Infrared Spectroscopy Analysis. Infrared spectra of the synthesized product were recorded on Agilent instrument in the range $400-4000 \mathrm{~cm}^{-1}$.

2.4.5. Photocatalytic Studies. Harmful organic dyes, namely, MG, EBT, MO, and MB, were degraded photochemically using KMHCF nanoparticles. The absorption spectra of the dye solutions were recorded using Agilent Pro spectrometer and the rate of degradation was observed in terms of change in intensity at $\lambda_{\max }$ of the dye. The degradation efficiency (\%) has been calculated as

$$
\text { Degradation efficiency }(\%)=\frac{\left(C_{0}-C\right)}{C_{0}} \times 100,
$$

where $C_{0}$ is the initial concentration of dye and $C$ is the concentration of dye after photoirradiation.

Different parameters such as catalyst amount, initial concentration of dye, initial $\mathrm{pH}$, and temperature of the dye solution were optimized.

\section{Results and Discussion}

In 1969 formula in case of metal hexacyanoferrates was given by Dolezal and Kourim [45]. The outer sphere ion M is present in +3 oxidation state. Chandra et al. reported that the geometry of $\left[\mathrm{Fe}(\mathrm{CN})_{6}\right]^{4-}$ is octahedral in which six $\mathrm{CN}^{-}$ ligands surround the central metal ion. $\mathrm{CN}^{-}$ligands being strong field ligands will forcefully pair up with 6 electrons present in the inner sphere of $\mathrm{Fe}^{2+}$ and a low-spin $\mathrm{t}_{2 \mathrm{~g}}{ }^{6}$ configuration is achieved. In addition a significant backbonding between the metal $\mathrm{d} \pi$ orbitals and the antibonding $\mathrm{p} \pi$ orbitals of the $\mathrm{CN}^{-}$ligand exists. The outer sphere metals $\mathrm{Fe}, \mathrm{Cu}, \mathrm{Co}$, and $\mathrm{Ni}$ get coordinated to the nitrogen end of the cyanide ligand present inside the $\left[\mathrm{Fe}(\mathrm{CN})_{6}\right]^{4-}$ sphere [46].

3.1. Characterization. Figure 2 shows the powder X-ray diffraction measurements (powder method, panalytical.X.Pert Pro) of the synthesized nanostructures. Interplanar spacing and the relative intensity data were found in good agreement with the JCPDS values (FeHCF Card number 73-0687, KCuHCF Card number 75-0024, KCoHCF Card number 75-0038, and KNiHCF Card number 23-0491). 


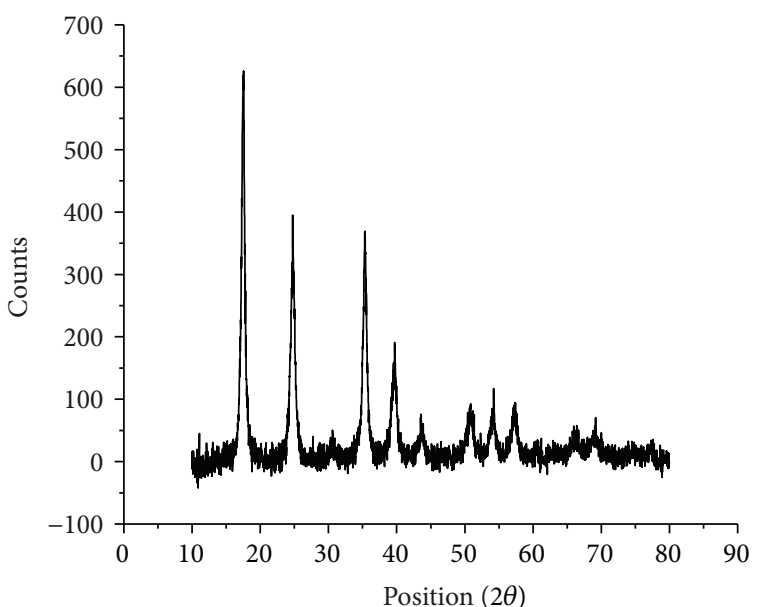

(a)

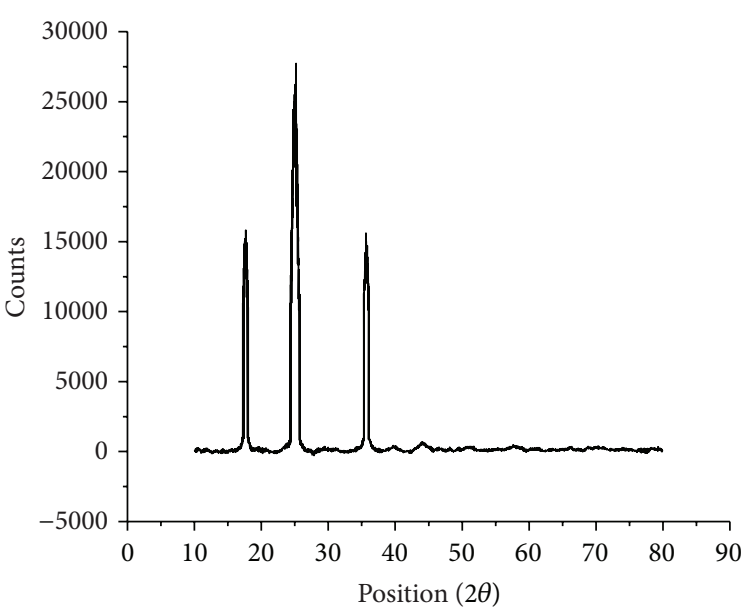

(c)

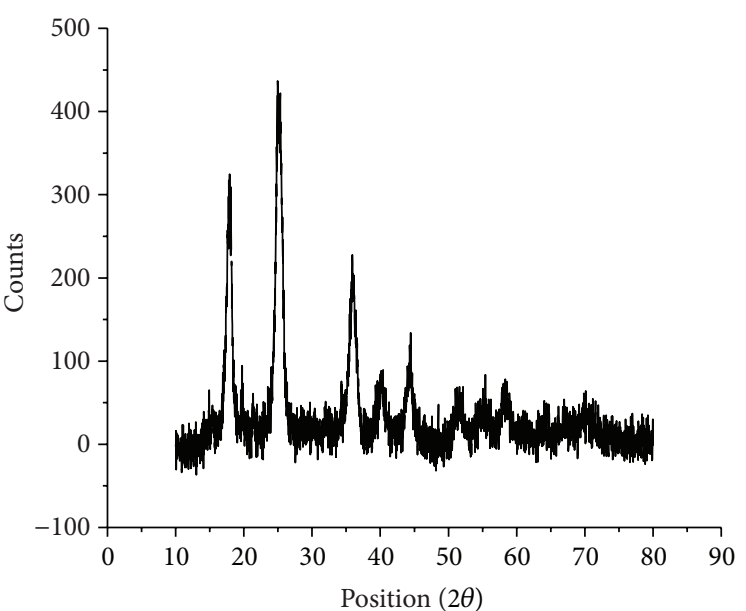

(b)

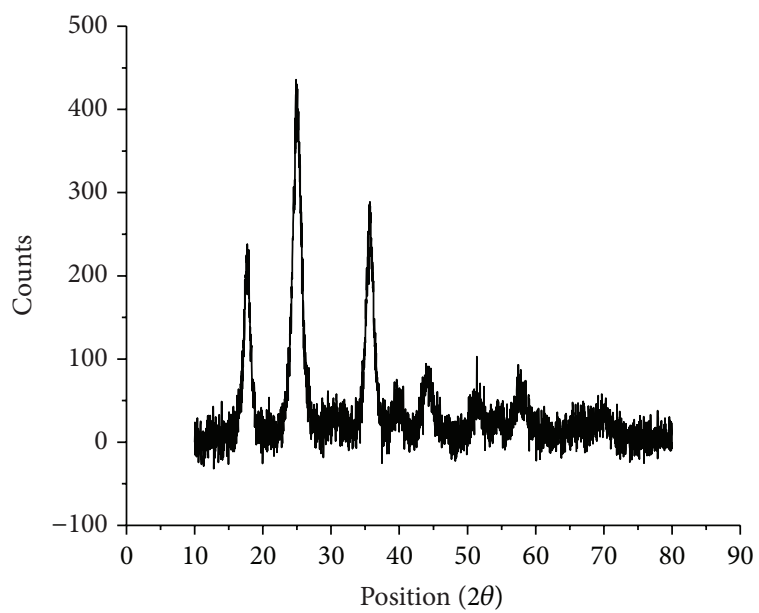

(d)

Figure 2: PXRD pattern of (a) FeHCF, (b) KCuHCF, (c) KCoHCF, and (d) KNiHCF nanoparticles.

The clear and sharp X-ray peaks indicated the high crystallinity of synthesized nanomaterials.

In case of FeHCF, KCuHCF, KCoHCF, and KNiHCF the maximum relative intensity (\%) was observed at $17.474^{\circ}$, $25.2620^{\circ}, 25.044^{\circ}$, and $25.02^{\circ}$ at $2 \theta$ scale along with $5.07114 \AA$,

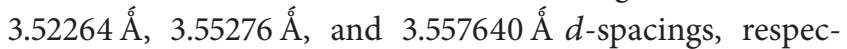
tively. The high intensity sharp peaks clearly show the high crystallinity of synthesized KMHCF nanostructures. The $2 \theta$ and $d$ values are given in Table 1 .

FE-SEM (Figure 3) analysis finally confirmed the synthesis of nanosized FeHCF and KMHCF nanoparticles with an average size below $50 \mathrm{~nm}$. Interestingly, different transition metal nanoparticles exhibited different sizes and surface morphology. All the nanoparticles were found to be distributed uniformly throughout the ferrocyanate network. Elemental composition of the synthesized nanoparticles was confirmed through Energy Dispersive Spectroscopic (EDS) analysis (Figure 4).

In FeHCF, the $\mathrm{C}, \mathrm{N}, \mathrm{O}$, and Fe showed weight\% 12.84, $13.82,3.44$, and 56.83 , whereas atomic $\%$ was found to be 29.51 ,
27.23, 5.94, and 28.09, respectively. In case of KCuHCF, the C, $\mathrm{N}, \mathrm{K}, \mathrm{Fe}$, and $\mathrm{Cu}$ showed weight\% 15.90, 24.00, 18.29, 19.15, and 22.66, along with atomic\% corresponding to $31.49,40.75$, $11.13,8.16$, and 8.48, respectively. Similarly, for KCoHCF the $\mathrm{C}, \mathrm{N}, \mathrm{O}, \mathrm{K}, \mathrm{Fe}$, and Co were found to contain weight $\% 16.11$, $19.66,3.33,21.60,18.32$, and 20.98 , whereas atomic\% exhibited was $32.01,33.51,4.97,13.19,7.83$, and 8.50, respectively. Also, in case of $\mathrm{KNiHCF}$ the $\mathrm{C}, \mathrm{N}, \mathrm{O}, \mathrm{K}, \mathrm{Fe}$, and Ni were observed to have weight $\% 21.51,28.25,7.29,16.80,12.55$, and 13.59; however atomic\% was found to be $34.77,39.17,8.85,8.34,4.36$, and 4.50 , respectively.

TEM was employed to characterize the exact size and shape of the $\mathrm{PB}$ and its analogue nanoparticles. Figure 5 clearly indicated the presence of well dispersed nanoparticles. Depending upon the nature of transition metal ion, the KMHCF nanoparticles exhibited diverse shapes and sizes. The most interesting fact observed was that all the KMHCF nanoparticles exhibited extremely small sizes, less than $50 \mathrm{~nm}$ (majority of them below $10 \mathrm{~nm}$ ). It was observed that FeHCF, $\mathrm{KCoHCF}, \mathrm{KCuHCF}$, and $\mathrm{KNiHCF}$ formed well dispersed 


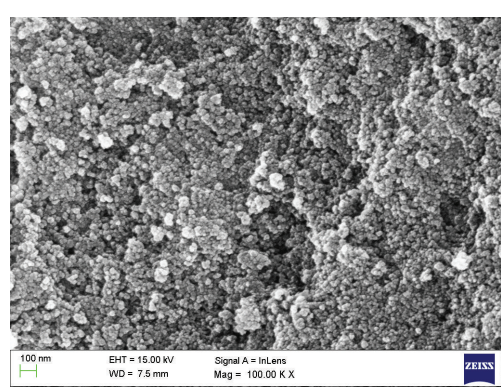

(a)

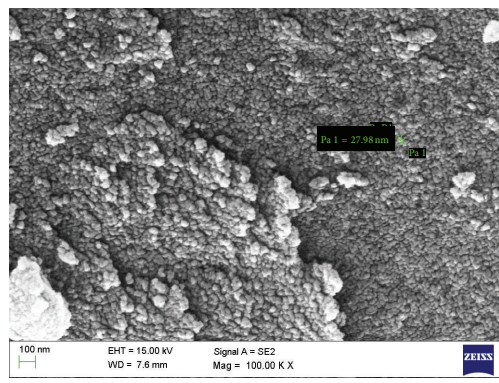

(c)

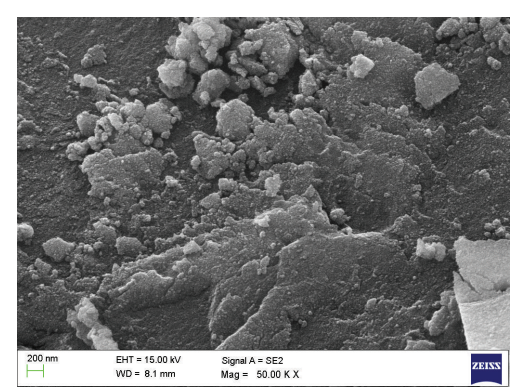

(b)

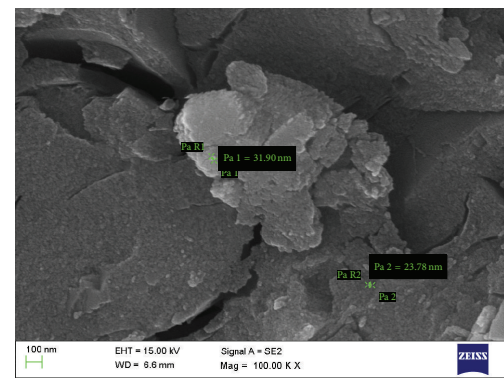

(d)

Figure 3: FE-SEM images of (a) Fe, (b) Ni, (c) Co, and (d) Cu HCF nanoparticles using Aegle marmelos.

TABLE 1: PXRD parameters of FeHCF and other different KMHCF nanostructures.

\begin{tabular}{|c|c|c|c|c|c|}
\hline Sample & Position $(2 \theta)$ & Height (cts) & FWHM & $d$-spacing $(\AA ̊)$ & Relative intensity (\%) \\
\hline \multirow{4}{*}{$\mathrm{FeHCF}$} & 17.474 & $425(7)$ & $0.525(9)$ & 5.07114 & 100.00 \\
\hline & 24.740 & $227(8)$ & $0.74(1)$ & 3.59570 & 53.48 \\
\hline & 35.309 & $237(5)$ & $0.61(1)$ & 2.53995 & 55.93 \\
\hline & 39.592 & $99(4)$ & $0.89(2)$ & 2.27449 & 23.33 \\
\hline \multirow{3}{*}{$\mathrm{KCuHCF}$} & 17.8270 & 198.38 & 0.8868 & 4.97150 & 90.79 \\
\hline & 25.2620 & 218.50 & 0.9642 & 3.52264 & 100.00 \\
\hline & 35.9171 & 124.35 & 1.1609 & 2.49830 & 56.91 \\
\hline \multirow{3}{*}{$\mathrm{KCoHCF}$} & 17.685 & $102(3)$ & $0.82(2)$ & 5.01098 & 58.98 \\
\hline & 25.044 & $173(3)$ & $1.04(2)$ & 3.55276 & 100.00 \\
\hline & 35.69 & $96(4)$ & $0.97(3)$ & 2.51360 & 55.61 \\
\hline \multirow{3}{*}{$\mathrm{KNiHCF}$} & 17.46 & $93(14)$ & $0.90(9)$ & 5.07388 & 39.51 \\
\hline & 25.02 & $234(22)$ & $1.61(5)$ & 3.55640 & 100.00 \\
\hline & 35.657 & $171(4)$ & $1.30(2)$ & 2.51592 & 73.06 \\
\hline
\end{tabular}

and diversified shaped nanoparticles with a narrow size distribution around $6.55 \mathrm{~nm}, 21.1 \mathrm{~nm}, 4.01 \mathrm{~nm}$, and $45.3 \mathrm{~nm}$, respectively.

FT-IR studies were also carried out to determine the various functional groups present in the synthesized products. It is well known that the single, broad band of the $v_{\mathrm{CN}}$ absorption of PB-structured materials in the range of $2000-2200 \mathrm{~cm}^{-1}$ is diagnostic of the C-bound metal ion and its oxidation state but is much less sensitive to the $\mathrm{N}$ bound metal ion and its oxidation state. Peak below $400 \mathrm{~cm}^{-1}$ corresponds to the metal ion peak. Its frequency varies depending upon the transition metal ion.
In case of FeHCF nanoparticles, FT-IR peaks were observed at $2066 \mathrm{~cm}^{-1}$ (CझN stretching), $598 \mathrm{~cm}^{-1}$ (Fe-C stretching), and $490 \mathrm{~cm}^{-1}$ (Fe-N stretching), whereas FT-IR spectra of KCoHCF nanoparticles showed peaks at $2087 \mathrm{~cm}^{-1}$ (C $\equiv \mathrm{N}$ stretching), $587 \mathrm{~cm}^{-1}$ (Fe-C stretching), and $455 \mathrm{~cm}^{-1}$ (Co-N stretching). In case of FT-IR spectrum of KCuHCF nanoparticles, peaks were observed at $2073 \mathrm{~cm}^{-1}(\mathrm{C} \equiv \mathrm{N}$ stretching), $588 \mathrm{~cm}^{-1}$ (Fe-C stretching), and $473 \mathrm{~cm}^{-1}$ (Cu$\mathrm{N}$ stretching). KNiHCF nanoparticles showed stretching at $2087 \mathrm{~cm}^{-1}$ (C三N stretching), $587 \mathrm{~cm}^{-1}$ (Fe-C stretching), and $455 \mathrm{~cm}^{-1}$ (Ni-N stretching). All the spectra are provided as supplementary information (Figure 1 in Supplementary 


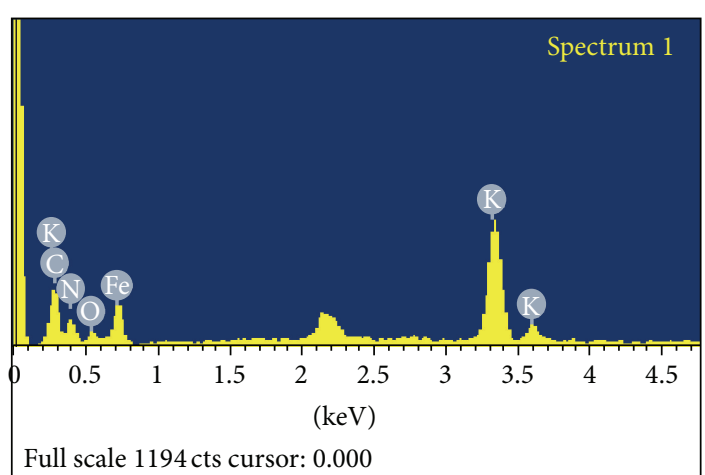

\begin{tabular}{lcc}
\hline Element & Weight (\%) & Atomic (\%) \\
\hline C K & 12.84 & 29.51 \\
N K & 13.82 & 27.23 \\
O K & 3.44 & 5.94 \\
K K & 13.07 & 9.23 \\
Fe K & 56.83 & 28.09 \\
Totals & 100.00 & \\
\hline
\end{tabular}

(a)

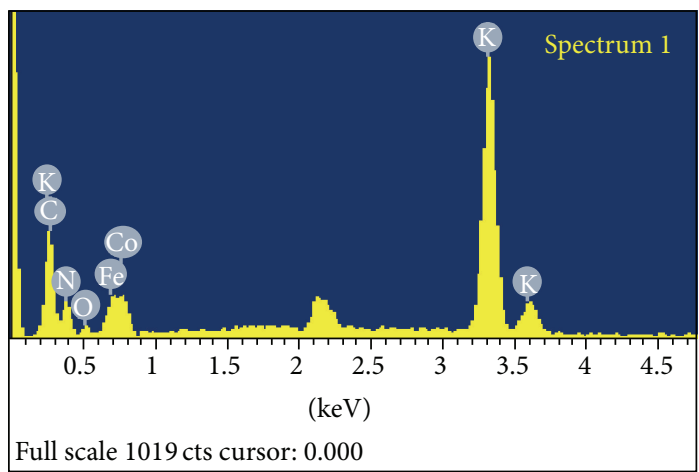

\begin{tabular}{lcc}
\hline Element & Weight (\%) & Atomic (\%) \\
\hline C K & 16.11 & 32.01 \\
N K & 19.66 & 33.51 \\
O K & 3.33 & 4.97 \\
K K & 21.60 & 13.19 \\
Fe K & 18.32 & 7.83 \\
Co K & 20.98 & 8.50 \\
Totals & 100.00 & \\
\hline
\end{tabular}

(c)

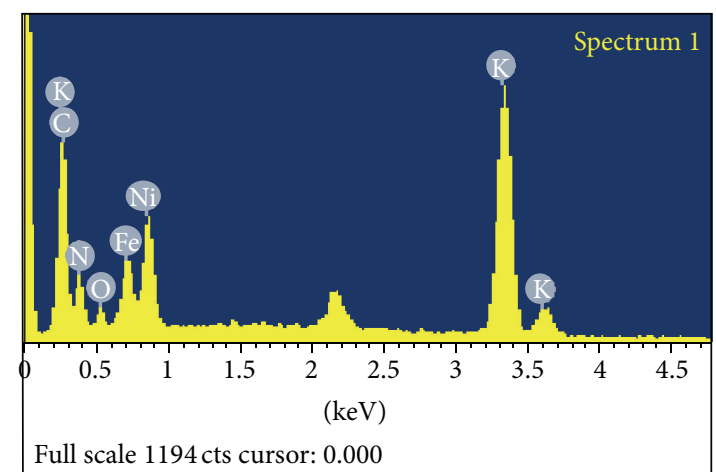

\begin{tabular}{lcc}
\hline Element & Weight (\%) & Atomic (\%) \\
\hline C K & 21.51 & 34.77 \\
N K & 28.25 & 39.17 \\
O K & 7.29 & 8.85 \\
K K & 16.80 & 8.34 \\
Fe K & 12.55 & 4.36 \\
Ni K & 13.59 & 4.50 \\
Totals & 100.00 & \\
\hline
\end{tabular}

(b)

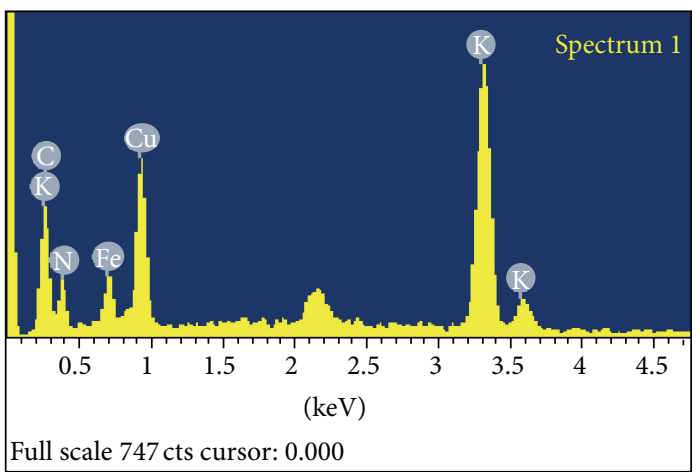

\begin{tabular}{lcc}
\hline Element & Weight (\%) & Atomic (\%) \\
\hline C K & 15.90 & 31.49 \\
N K & 24.00 & 40.75 \\
K K & 18.29 & 11.13 \\
Fe K & 19.15 & 8.16 \\
Cu L & 22.66 & 8.48 \\
Totals & 100.00 & \\
\hline
\end{tabular}

(d)

Figure 4: EDX pattern of (a) Fe, (b) Ni, (c) Co, and (d) Cu HCF nanoparticles using Aegle marmelos.

Material available online at http://dx.doi.org/10.1155/2016/ 2715026).

3.2. Photocatalytic Activity. Synthesized potassium metal hexacyanoferrate nanoparticles (excluding FeHCF) were used for the degradation of MG, EBT, MO, and MB organic dyes. Absorbance measurement was carried out at regular time intervals. Different parameters such as photocatalyst dose, initial concentration of dye, initial $\mathrm{pH}$, and temperature of the dye degradation were studied for getting the maximal degradation. The prime motive behind the synthesis of KMHCF nanoparticles and their evaluation as photocatalytic agents for the degradation of dyes was to achieve maximum degradation of organic dyes which are normally present in the textile effluents and are the cause of environmental hazards.

Absorbance was recorded after each interval of 20 minutes and carried out up to 2 hours. Absorbance intensity was found to decrease continuously with increase in time interval. Following trend was observed during the photocatalytic 


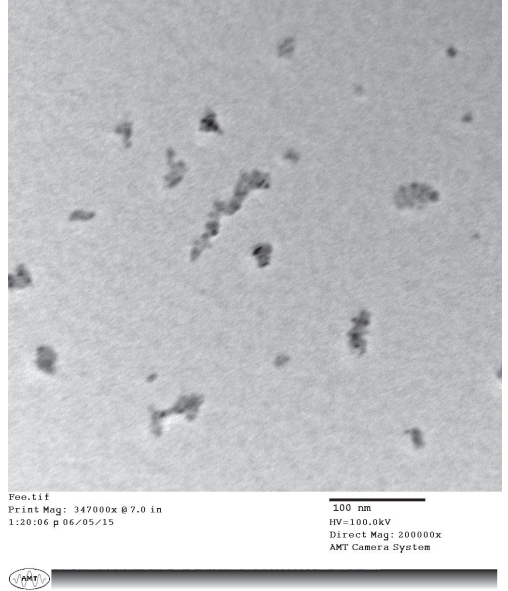

(a)

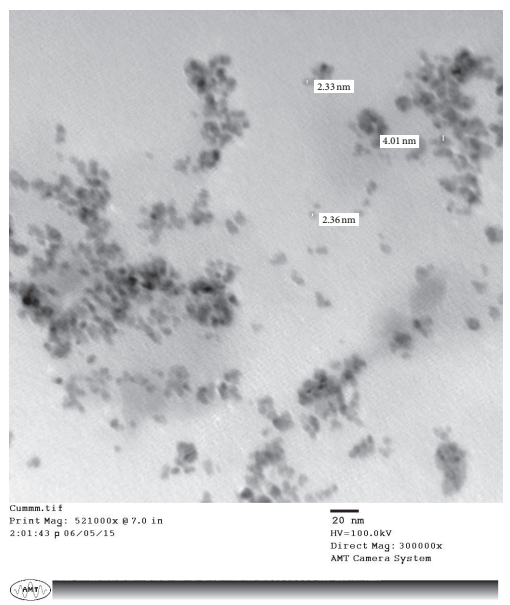

(c)

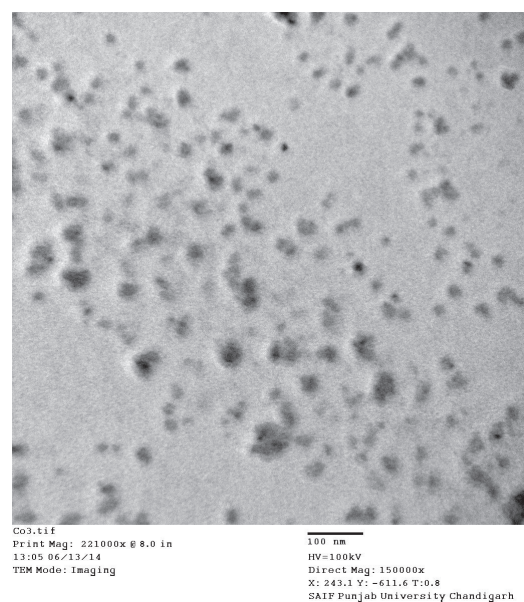

(b)

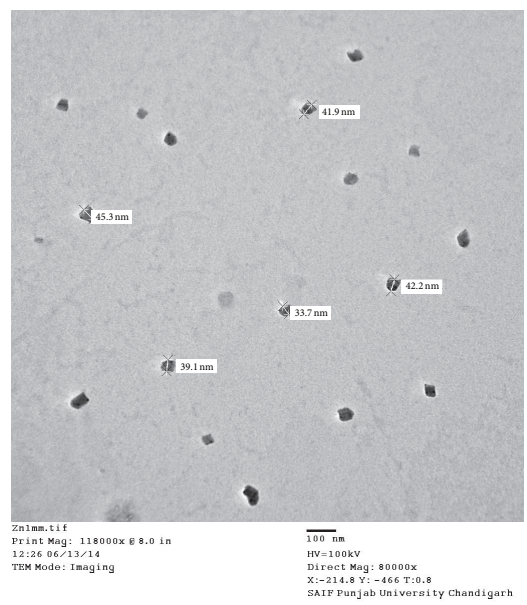

(d)

Figure 5: TEM images of (a) FeHCF, (b) KCoHCF, (c) KCuHCF, and (d) KNiHCF nanoparticles.

TABle 2: Degradation of different dyes using different KMHCF nanoparticles.

\begin{tabular}{lcc}
\hline Dye & Nanostructures & \% dye degradation \\
\hline \multirow{2}{*}{ MG } & KCuHCF & 96.06 \\
& KNiHCF & 95.00 \\
& KCoHCF & 90.87 \\
\hline \multirow{2}{*}{ EBT } & KCuHCF & 83.87 \\
& KNiHCF & 79.84 \\
& KCoHCF & 75.81 \\
\hline \multirow{2}{*}{ MO } & KCuHCF & 63.67 \\
& KNiHCF & 59.42 \\
& KCoHCF & 58.20 \\
\multirow{2}{*}{ MB } & KCuHCF & 94.72 \\
& KNiHCF & 91.35 \\
& KCoHCF & 89.28 \\
\hline
\end{tabular}

$\mathrm{MG}=$ Malachite Green, EBT $=$ Eriochrome Black T, MO = Methyl Orange, and $\mathrm{MB}=$ Methylene Blue. degradation of different toxic dyes: MG (96.06\%, KCuHCF) > MB $(94.72 \%, \mathrm{KCuHCF})>\operatorname{EBT}(83.87 \%, \mathrm{KCuHCF})>\mathrm{MO}$ (63.71\%, KCuHCF). The maximum photocatalytic degradation was observed in case of $\mathrm{MG}$ dye using $\mathrm{KCuHCF}$ nanoparticles. However, minimum photodegradation was found with $\mathrm{MO}$ dye in presence of KCoHCF nanoparticles. Percent degradation of different dyes using various KMHCF nanoparticles is given in Table 2.

Degradation of dyes is due to the reason that nanoparticle catalysts used are semiconductor in nature which upon photoillumination generate electron-hole pairs. The generation of electron-hole pairs is responsible for the photodegradation of different dyes [47]. Further the photodegradation of dyes was found to be initial dye concentration dependent. Maximum photocatalytic degradation was observed at $5 \mathrm{ppm}$ concentration in case of MG, EBT, MO, and MB. Since initially it is the adsorption of dye on the nanoparticles followed by the photocatalytic degradation process, therefore the possible explanation could be that at this dye concentration maximum number of active sites on the surface of catalyst is available for 
adsorption of dyes. As the concentration increases, the active sites for adsorption present on nanoparticles get blocked; thus the rate of dye degradation decreases [48]. In case of temperature dependent dye degradation studies, it was found that, with increase in temperature, relative absorption intensity decreased and negligible dye degradation was observed. This could be due to decrease in dye adsorption on the surface of nanoparticles with increase in temperature, resulting in decreased dye degradation. Thus, metal hexacyanoferrate nanoparticles in case of dye degradation act as a photocatalyst not thermocatalyst [49]. However, photodegradation of all the dyes was found to be dependent upon the concentration of the catalyst. In case of $\mathrm{KCuHCF}$ nanoparticles at the concentration of $15 \mathrm{mg}$ per $10 \mathrm{~mL}$ of each dye maximum photodegradation of $96.06 \%, 83.87 \%$, $94.72 \%$, and $63.71 \%$ was found in case of MG, EBT, MB, and $\mathrm{MO}$, respectively. However, in case of KNiHCF nanoparticles, maximum photodegradation of MG, EBT, MO, and MB was found to be $95 \%, 79.84 \%, 59.42 \%$, and $91.35 \%$, respectively. KCoHCF nanoparticles degraded the dyes MG, EBT, MO, and $\mathrm{MB}$ to the extent of $90.87 \%, 75.81 \%, 58.20 \%$, and $89.28 \%$, respectively. This could be due to the reason that, at preoptimized dye concentration, too high or low dose of the catalyst was not a favorable condition. A moderate catalyst concentration $(15 \mathrm{mg} / 10 \mathrm{~mL})$ was found to be optimal for the decomposition of MG, EBT, MO, and MB [50]. $\mathrm{pH}$ was found to play an important role in the photocatalytic degradation of dyes. Dye degradation was found to increase with increase in $\mathrm{pH}$. However, maximum degradation was found at $\mathrm{pH}$ 7.0. Further increase in $\mathrm{pH}$ resulted in decreased dye degradation. This could be due to the ion screening effects of $\mathrm{H}^{+}$ions under acidic conditions and $\mathrm{OH}^{-}$ions in alkaline medium. Ion screening effects of $\mathrm{H}^{+}$ions at low $\mathrm{pH}$ and $\mathrm{OH}^{-}$ ions under alkaline conditions have the adverse impact on the adsorption of dyes on the KMHCF nanoparticles and hence decreased dye degradation was observed [47]. KMHCF nanoparticles are insoluble in water as well as fairly stable in acids like $\mathrm{HCl}, \mathrm{HNO}_{3}$, and $\mathrm{H}_{2} \mathrm{SO}_{4}$ as well as bases like $\mathrm{NaOH}$ and $\mathrm{KOH}$. Thus, after the completion of dye degradation reactions, catalysts were recovered and could be used again for similar further reactions.

3.3. Adsorption Isotherms. Adsorption isotherms (Figure 6) of MG, EBT, MO, and MB in the present case clearly show that adsorption is fast in all the cases and the isotherms are regular, positive, and concave to the concentration axis. Adsorption data can be represented through Langmuir adsorption isotherms which assume the formation of a monolayer of solute molecules on the surface of the adsorbent [51]. A typical graph of $C_{e} / X_{e}$ v/s $C_{e}$ of all the dyes is a straight line (Figure 7). The adsorption data was fitted in Langmuir adsorption equation:

$$
\frac{C_{e}}{X_{e}}=\frac{1}{k_{L} X_{m}}+\frac{C_{e}}{X_{m}}
$$

or

$$
\frac{1}{X_{e}}=\frac{1}{C_{e}}\left(\frac{1}{k_{L} X_{m}}\right)+\frac{1}{X_{m}}
$$

TABLE 3: Langmuir constants for different dyes adsorption on various KMHCF nanoparticles.

\begin{tabular}{llcc}
\hline Dye & Sample & $X_{m}(\mathrm{mg} / \mathrm{g})$ & $k_{L}\left(\mathrm{dm}^{3} / \mathrm{mol}\right)$ \\
\hline \multirow{3}{*}{ MG } & KCuHCF & 4.856 & 0.7483 \\
& KNiHCF & 3.984 & 0.9051 \\
& KCoHCF & 4.608 & 1.057 \\
\hline \multirow{2}{*}{ EBT } & KCuHCF & 4.524 & 2.194 \\
& KNiHCF & 4.014 & 1.956 \\
& KCoHCF & 3.920 & 2.716 \\
\hline \multirow{3}{*}{ MO } & KCuHCF & 4.49 & 8.54 \\
& KNiHCF & 3.094 & 7.00 \\
& KCoHCF & 2.923 & 6.170 \\
\hline \multirow{3}{*}{ MB } & KCuHCF & 3.799 & 0.342 \\
& KNiHCF & 3.658 & 0.487 \\
& KCoHCF & 3.895 & 0.692 \\
\hline
\end{tabular}

$\mathrm{MG}=$ Malachite Green, EBT $=$ Eriochrome Black $\mathrm{T}, \mathrm{MO}=$ Methyl Orange and $\mathrm{MB}=$ Methylene Blue; $X_{m}=$ amount of dye adsorbed; $k_{L}=$ Langmuir adsorption constant.

where $C_{e}$ is the equilibrium concentration of the dye solution; $X_{e}$ is the amount of dye adsorbed per gram weight of adsorbent; $X_{m}$ is the amount of dye adsorbed at saturation; $k_{L}$ is the Langmuir adsorption constant. $k_{L}$ and $X_{m}$ values were determined and shown in Table 3. In case of dye adsorption on KMHCF nanoparticles, $X_{m}$ values followed the trend: $4.856 \mathrm{mg} / \mathrm{g}$ (Malchite Green adsorbed on KCuHCF nanoparticles, i.e., MG-ad-KCuHCF) > $4.608 \mathrm{mg} / \mathrm{g}$ (MGad-KCoHCF) $>4.525 \mathrm{mg} / \mathrm{g}$ (EBT-ad-KCuHCF) $>4.49 \mathrm{mg} / \mathrm{g}$ $(\mathrm{MO}-\mathrm{ad}-\mathrm{KCuHCF})>4.014 \mathrm{mg} / \mathrm{g}$ (EBT-ad-KNiHCF) > $3.984 \mathrm{mg} / \mathrm{g}$ (MG-ad-KNiHCF) > $3.920 \mathrm{mg} / \mathrm{g}$ (EBT-ad$\mathrm{KCoHCF})>3.895 \mathrm{mg} / \mathrm{g}(\mathrm{MB}-\mathrm{ad}-\mathrm{KCoHCF})>3.799 \mathrm{mg} / \mathrm{g}$ (MB-ad-KCuHCF) > $3.658 \mathrm{mg} / \mathrm{g}$ (MB-ad-KNiHCF) > $3.094 \mathrm{mg} / \mathrm{g}$ (MO-ad-KNiHCF) > $2.923 \mathrm{mg} / \mathrm{g}$ (MO-ad$\mathrm{KCoHCF})$. However, $k_{L}$ values were found to follow the trend $8.54 \mathrm{dm}^{3} / \mathrm{mol}$ (MO-ad-KCuHCF) $>7.00 \mathrm{dm}^{3} / \mathrm{mol}$ $(\mathrm{MO}-\mathrm{ad}-\mathrm{KNiHCF})>6.170 \mathrm{dm}^{3} / \mathrm{mol}(\mathrm{MO}-\mathrm{ad}-\mathrm{KCoHCF})>$ $2.716 \mathrm{dm}^{3} / \mathrm{mol}\left(\right.$ EBT-ad-KCoHCF) $>2.194 \mathrm{dm}^{3} / \mathrm{mol}($ EBTad-KCuHCF) > $1.956 \mathrm{dm}^{3} / \mathrm{mol}$ (EBT-ad-KNiHCF) > $1.057 \mathrm{dm}^{3} / \mathrm{mol}$ (MG-ad-KCoHCF) $>0.905 \mathrm{dm}^{3} / \mathrm{mol}$ (MGad-KNiHCF) > $0.7483 \mathrm{dm}^{3} / \mathrm{mol}$ (MG-ad-KCuHCF) > $0.692 \mathrm{dm}^{3} / \mathrm{mol}(\mathrm{MB}-\mathrm{ad}-\mathrm{KCoHCF})>0.487 \mathrm{dm}^{3} / \mathrm{mol}(\mathrm{MB}-$ ad-KNiHCF) $>0.342 \mathrm{dm}^{3} / \mathrm{mol}$ (MB-ad-KCuHCF).

Maximum $k_{L}$ value was found in case of adsorption of MO on KCuHCF nanoparticles whereas minimum value was observed with the adsorption of $\mathrm{MB}$ on KCuHCF nanostructures. Further it has been observed that maximum $k_{L}$ values were shown by the adsorption of MO dye on different KMHCF nanoparticles, whereas minimum $k_{L}$ values were found with the adsorption of $\mathrm{MB}$ on different KMHCF nanoparticles. Higher $X_{m}$ values, that is, adsorption of $\mathrm{MG}$ on $\mathrm{KCuHCF}$ nanoparticles, may be due to the interaction of $\mathrm{N}$-atoms of MG with the nanoparticles [52].

Since KMHCFs are semiconducting materials and molecular excitation takes place easily, thereby generating electrons and holes in between conduction and valence bands, this is 


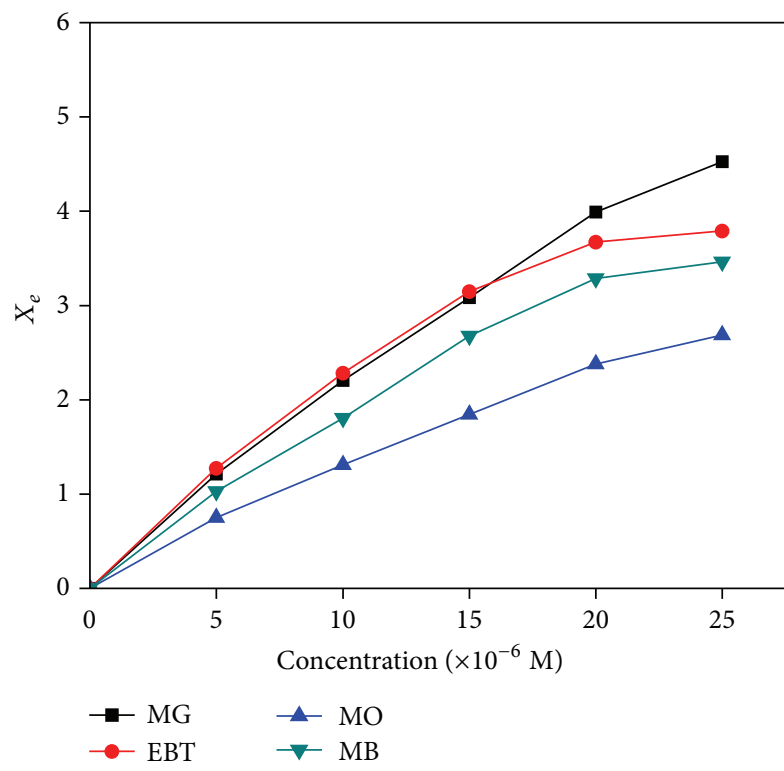

(a)

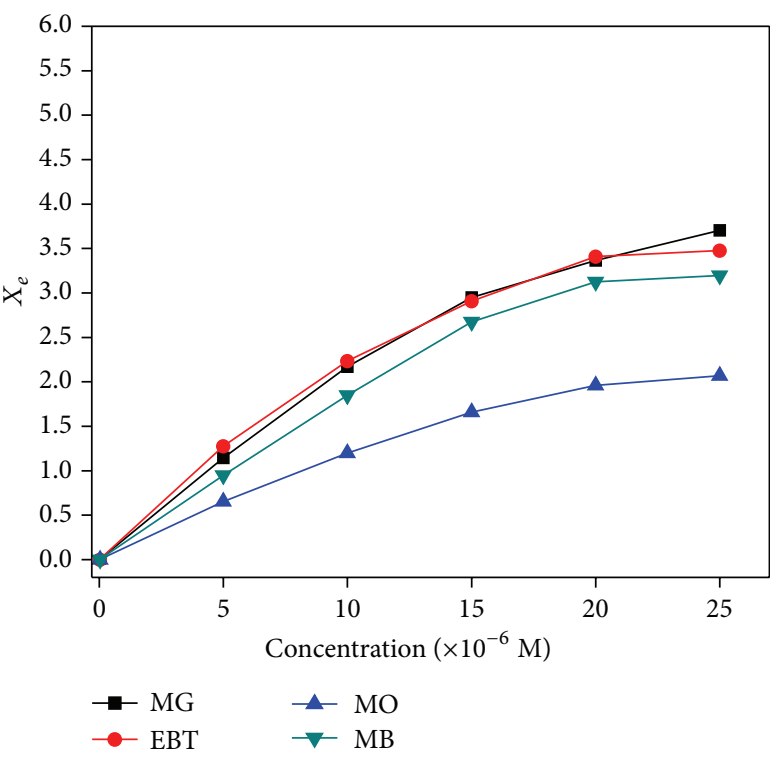

(b)

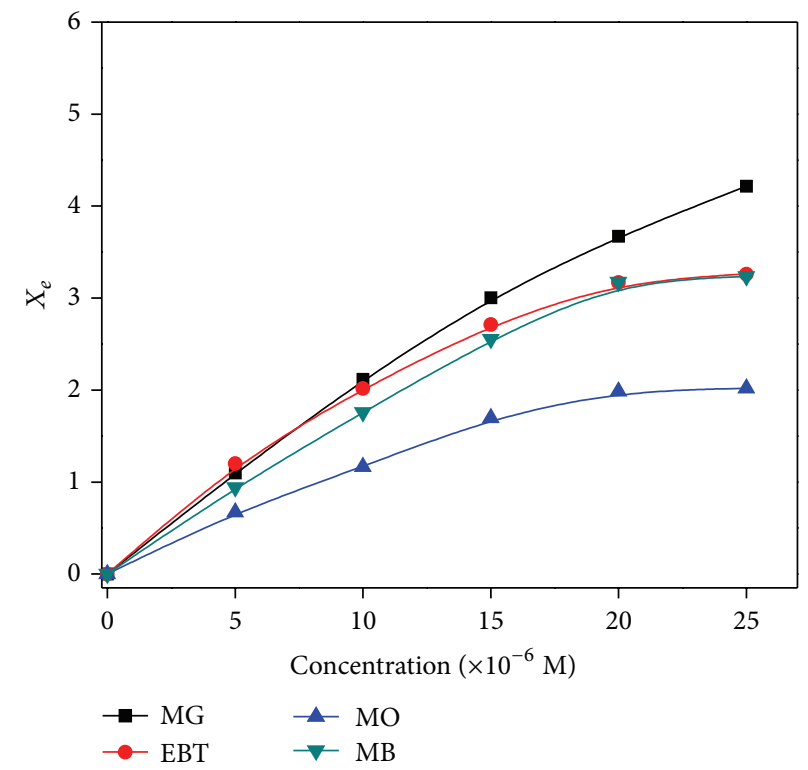

(c)

Figure 6: Adsorption isotherms for adsorption of MG, EBT, MO, and MB dyes on (a) KCuHCF, (b) KNiHCF, and (c) KCoHCF nanoparticles.

followed by a series of chemical reactions leading to the formation of hydroxyl free radicals. It is the $\mathrm{OH}^{*}$ which leads to the photodegradation of harmful organic dyes. Since it is the adsorption of the dye which takes place initially on the surface of adsorbent and afterwards is followed by dye degradation process, therefore, the proposed reaction sequence for the degradation of toxic organic dye MB in presence of KMHCF nanoparticles is given in Figure 8 (degradation mechanism for MG, EBT, and MO has been given as supplementary information as Figures 2, 3, and 4).

3.4. Thermodynamic Parameters. Dependence of $k_{L}$ (equilibrium constant) with temperature can be used to predict thermodynamics parameters, namely, Gibb's free energy change $\left(\Delta G^{\circ}\right)$, enthalpy change $\left(\Delta H^{\circ}\right)$, and entropy change $\left(\Delta S^{\circ}\right)$ associated with the dye adsorption process. These parameters were determined using the following equations:

$$
\begin{aligned}
\Delta G^{\circ} & =-R T k_{L}, \\
\ln k_{L} & =\frac{-\Delta G^{\circ}}{R T}=\frac{-\Delta H^{\circ}}{R T}+\frac{\Delta S^{\circ}}{R} .
\end{aligned}
$$

Plot of $\ln k_{L} \mathrm{v} / \mathrm{s} 1 / T$ yields a straight line. The slope as well as intercept of this plot gives the values of $\Delta H^{\circ}$ and $\Delta S^{\circ}$, respectively. The energy parameters $\Delta G^{\circ}, \Delta H^{\circ}$, and $\Delta S^{\circ}$ for MG, EBT, MO, and MB are given in Table 4. 


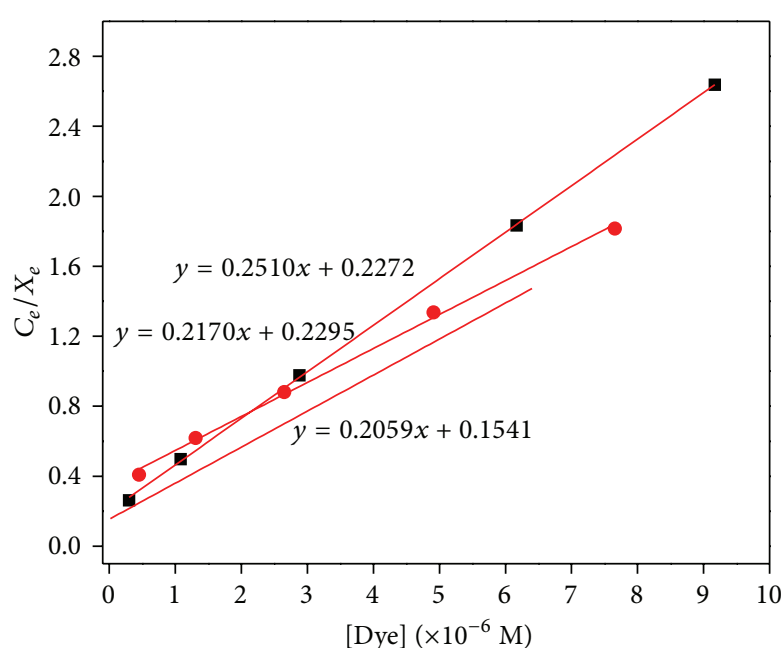

- KCuHCF

- $\mathrm{KNiHCF}$

- $\mathrm{KCoHCF}$

(a)

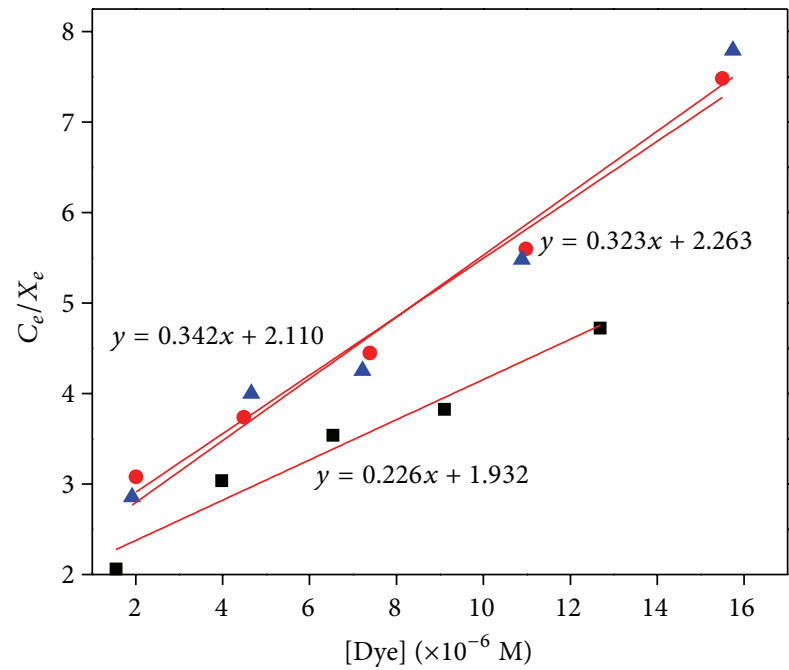

- $\mathrm{KCuHCF}$

- $\mathrm{KNiHCF}$

A $\mathrm{KCoHCF}$

(c)

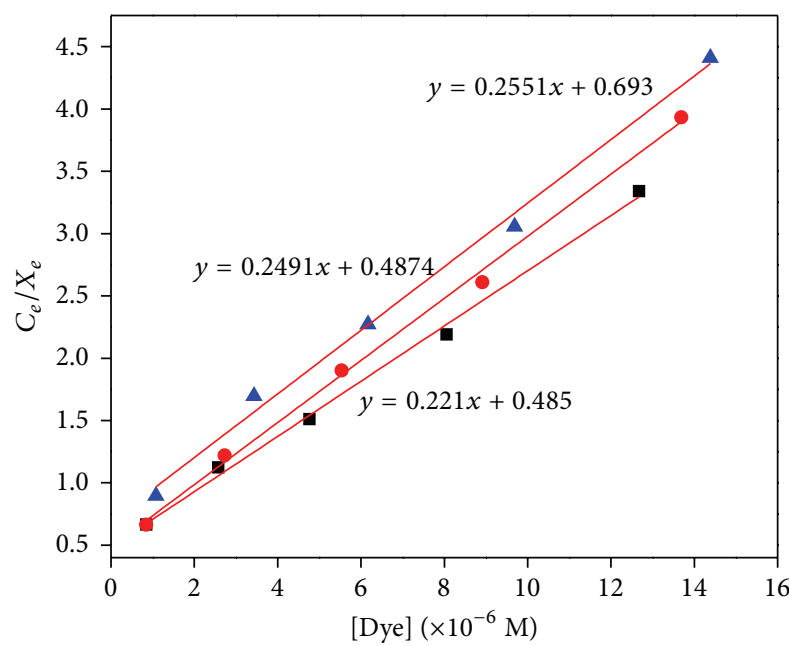

- KCuHCF

- $\mathrm{KNiHCF}$

- $\mathrm{KCoHCF}$

(b)

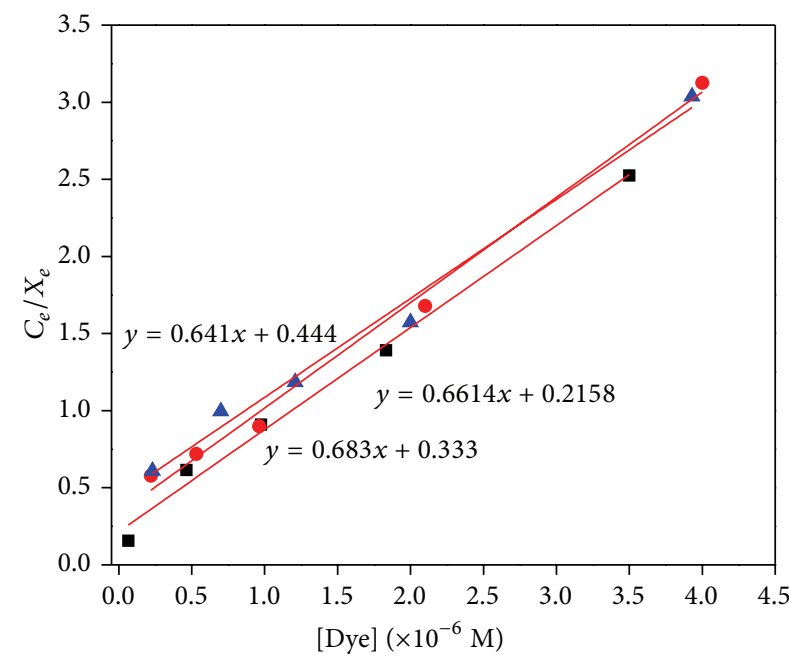

- $\mathrm{KCuHCF}$

- $\mathrm{KNiHCF}$

\ $\mathrm{KCoHCF}$

(d)

FIGURE 7: Langmuir isotherms for adsorption of (a) MG, (b) EBT, (c) MO, and (d) MB on KMHCF nanoparticles.

The negative values of $\Delta G^{\circ}$ at all temperatures suggest that the dye adsorption on the nanoparticles is spontaneous. The negative values of $\Delta H^{\circ}$ indicate that the nature of adsorption is exothermic. The positive values of $\Delta S^{\circ}$ suggest increased randomness at the solid/liquid interface during the adsorption of dyes onto different KMHCF nanostructures.

\section{Conclusions}

Monodisperse KMHCF nanoparticles (FeHCF, KCuHCF, $\mathrm{KNiHCF}$, and KCoHCF) using Aegle marmelos (bael) as a biosurfactant were synthesized through a green route. Plant based biosurfactant provides an environmentally friendly method since the route eliminates the use of toxic chemicals. This bioassisted approach led to instantaneous formation of nanoparticles with uniform distribution at room temperature. Synthesized nanoparticles were evaluated as photocatalyst for the degradation of MG, EBT, MO, and MB dyes. Different process parameters like photocatalyst dose, initial dye concentration, $\mathrm{pH}$, and temperature were studied in order to get the maximum dye degradation. MG was found to degrade to the maximum extent $(96.06 \%)$ whereas minimum degradation was found with $\mathrm{MO}(58.20 \%)$ in presence of KCuHCF, $\mathrm{KCoHCF}$ nanoparticles, respectively. EBT, $\mathrm{MB}$, and $\mathrm{MO}$ were 
<smiles>CN(C)c1ccc2nc3ccc(=[N+](C)C)cc-3sc2c1</smiles>

$\mathrm{KMHCF}+h v \rightarrow \mathrm{KMHCF}\left(\mathrm{e}^{-} \mathrm{CB}+\mathrm{h}^{+} \mathrm{VB}\right)$

$$
\mathrm{h}^{+}+\mathrm{H}_{2} \mathrm{O} \rightarrow \mathrm{H}^{+}+{ }^{\cdot} \mathrm{OH}
$$<smiles>C=c1ccc2c(c1)Sc1cc(N(C)C)ccc1N=2</smiles>

MB dye (excited state)

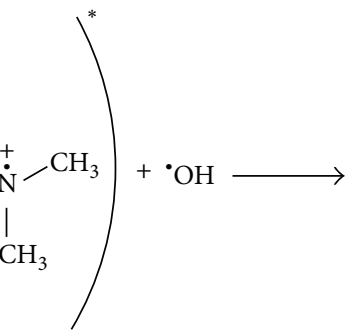

$\left.\begin{array}{l}+ \\ \stackrel{\mathrm{N}}{\mathrm{C}}-\mathrm{CH}_{3}\end{array}\right)+\cdot \mathrm{OH}$

$\mathrm{OH}$<smiles>CN(C)c1ccc2nc3ccc(=[N+](C)C)cc-3sc2c1</smiles>

MB dye (colourless form)<smiles>C[14C](=[18O])c1ccc2nc3ccc(=[N+](C)C)cc-3sc2c1</smiles>

MB dye (colourless form)

FIGURE 8: Photocatalytic degradation of MB in presence of KMHCF nanoparticles.

TABLE 4: Thermodynamic parameters of different dyes adsorption on various KMHCF nanoparticles.

\begin{tabular}{|c|c|c|c|c|c|c|}
\hline \multirow{3}{*}{ Dye } & \multirow{3}{*}{ Sample } & \multicolumn{5}{|c|}{ Thermodynamic parameters } \\
\hline & & \multicolumn{3}{|c|}{$-\Delta G^{\circ}\left(\mathrm{kJ} \mathrm{mol}{ }^{-1}\right)$} & \multirow{2}{*}{$\Delta H^{\circ}\left(\mathrm{kJ} \mathrm{mol}^{-1}\right)$} & \multirow{2}{*}{$\Delta S^{\circ}\left(\mathrm{kJ} \mathrm{mol}{ }^{-1} \mathrm{~K}^{-1}\right)$} \\
\hline & & $30^{\circ} \mathrm{C}$ & $40^{\circ} \mathrm{C}$ & $50^{\circ} \mathrm{C}$ & & \\
\hline \multirow{3}{*}{ MG } & KCuHCF & 9.387 & 10.271 & 10.768 & -1361.42 & 8.237 \\
\hline & KNiHCF & 9.866 & 10.749 & 11.440 & -1651.25 & 9.376 \\
\hline & KCoHCF & 10.257 & 10.868 & 11.563 & -1112.78 & 7.738 \\
\hline \multirow{3}{*}{ EBT } & $\mathrm{KCuHCF}$ & 12.097 & 12.604 & 13.051 & -277.82 & 5.722 \\
\hline & $\mathrm{KNiHCF}$ & 11.807 & 12.398 & 13.023 & -773.59 & 7.237 \\
\hline & $\mathrm{KCoHCF}$ & 12.634 & 13.164 & 13.773 & -537.55 & 6.784 \\
\hline \multirow{3}{*}{ MO } & KCuHCF & 15.521 & 16.093 & 16.659 & -202.054 & 6.828 \\
\hline & $\mathrm{KNiHCF}$ & 15.019 & 15.555 & 16.102 & -161.480 & 6.494 \\
\hline & $\mathrm{KCoHCF}$ & 14.702 & 15.233 & 15.752 & -142.235 & 6.306 \\
\hline \multirow{3}{*}{$\mathrm{MB}$} & KCuHCF & 7.414 & 7.814 & 8.250 & -612.145 & 4.961 \\
\hline & KNiHCF & 8.305 & 8.804 & 9.189 & -600.317 & 5.284 \\
\hline & $\mathrm{KCoHCF}$ & 9.190 & 9.643 & 10.027 & -411.435 & 5.009 \\
\hline
\end{tabular}

$\Delta G^{\circ}=$ Gibb's free energy change, $\Delta H^{\circ}=$ enthalpy change, and $\Delta S^{\circ}=$ entropy change. 
found to show maximum degradation of $83.87 \%, 94.72 \%$, and 63.71\% using KCuHCF nanoparticles; adsorbate dose $15 \mathrm{mg}$; each dye concentration $5 \mathrm{ppm}$ and temperature, ambient. Thus, KMHCF nanoparticles are promising agents for the treatment of textile effluents containing harmful organic dyes.

\section{Conflict of Interests}

The authors declare that there is no conflict of interests regarding the publication of this paper.

\section{Acknowledgments}

One of the authors, Ms. Vidhisha Jassal, is thankful to Ministry of Human Resource Development (MHRD), New Delhi, for providing financial assistance. Authors are also thankful to FIST-DST, New Delhi, for providing the equipment (FTIR and UV-VIS) used in characterization of the samples.

\section{References}

[1] N. R. de Tacconi, K. Rajeshwar, and R. O. Lezna, "Metal hexacyanoferrates: electrosynthesis, in situ characterization, and applications," Chemistry of Materials, vol. 15, no. 16, pp. 3046-3062, 2003.

[2] L. Catala, T. Gacoin, J.-P. Boilot et al., "Cyanide-bridged CrIIINiII superparamagnetic nanoparticles," Advanced Materials, vol. 15, no. 10, pp. 826-829, 2003.

[3] T. Uemura and S. Kitagawa, "Prussian blue nanoparticles protected by poly(vinylpyrrolidone)," Journal of the American Chemical Society, vol. 125, no. 26, pp. 7814-7815, 2003.

[4] T. Uemura, M. Ohba, and S. Kitagawa, "Size and surface effects of prussian blue nanoparticles protected by organic polymers," Inorganic Chemistry, vol. 43, no. 23, pp. 7339-7345, 2004.

[5] S. Ferlay, T. Mallah, R. Ouahès, P. Veillet, and M. Verdaguer, "A room-temperature organometallic magnet based on Prussian blue," Nature, vol. 378, no. 6558, pp. 701-703, 1995.

[6] O. Sato, T. Iyoda, A. Fujishima, and K. Hashimoto, "Electrochemical tunable magnetic phase transition in a high-Tc chromium cyanide thin film," Science, vol. 271, no. 5245, pp. 4951, 1996.

[7] S. Ohkoshi, Y. Abe, A. Fujishima, and K. Hashimoto, "Design and preparation of a novel magnet exhibiting two compensation temperatures based on molecular field theory," Physical Review Letters, vol. 82, no. 6, pp. 1285-1288, 1999.

[8] D. Luneau, "Molecular magnets," Current Opinion in Solid State \& Materials Science, vol. 5, no. 2, pp. 123-129, 2001.

[9] K. R. Dunbar and R. A. Heintz, "Chemistry of transition metal cyanide compounds: modern perspectives," Progress in Inorganic Chemistry, vol. 45, pp. 283-291, 2007.

[10] M. Pyrasch, A. Toutianoush, W. Jin, J. Schnepf, and B. Tieke, "Self-assembled films of Prussian Blue and analogues: optical and electrochemical properties and application as ion-sieving membranes," Chemistry of Materials, vol. 15, no. 1, pp. 245-254, 2003.

[11] N. F. Zakharchuk, N. Naumov, R. Stösser, U. Schröder, F. Scholz, and H. Mehner, "Solid state electrochemistry, X-ray powder diffraction, magnetic susceptibility, electron spin resonance, Mössbauer and diffuse reflectance spectroscopy of mixed
iron(III)-cadmium(II) hexacyanoferrates," Journal of Solid State Electrochemistry, vol. 3, no. 5, pp. 264-276, 1999.

[12] J. G. Moore, E. J. Lochner, C. Ramsey, N. S. Dalal, and A. E. Stiegman, "Transparent, superparamagnetic $\mathrm{K}_{x}^{\mathrm{I}} \mathrm{Co}_{y}^{\mathrm{II}}\left[\mathrm{Fe}^{\mathrm{III}}(\mathrm{CN})_{6}\right]$-silica nanocomposites with tunable photomagnetism," Angewandte Chemie-International Edition, vol. 42, no. 24, pp. 2741-2743, 2003.

[13] L. Wang, Y. Lu, J. Liu et al., "A superior low-cost cathode for a Na-Ion battery," Angewandte Chemie-International Edition, vol. 52, no. 7, pp. 1964-1967, 2013.

[14] Y. Yue, A. J. Binder, B. Guo et al., "Mesoporous prussian blue analogues: template-free synthesis and sodium-ion battery applications," Angewandte Chemie-International Edition, vol. 53, no. 12, pp. 3134-3137, 2014.

[15] M. Pasta, C. D. Wessells, N. Liu et al., "Full open-framework batteries for stationary energy storage," Nature Communications, vol. 5, article 3007, 2014.

[16] V. Vo, N. Van Minh, H. I. Lee, J. M. Kim, Y. Kim, and S. J. Kim, "Synthesis and characterization of Co-Fe Prussian blue nanoparticles within MCM-41," Materials Research Bulletin, vol. 44 , no. 1, pp. 78-81, 2009.

[17] S. Singh, D. V. S. Jain, and M. L. Singla, "In-situ electrochemical synthesis of Prussian blue composite with gold nanoparticles and its application in hydrogen peroxide biosensor," Advanced Materials Letters, vol. 6, pp. 99-103, 2015.

[18] A. Cabrera-García, A. Vidal-Moya, Á. Bernabeu, J. SánchezGonzález, E. Fernández, and P. Botella, "Gd-Si oxide mesoporous nanoparticles with pre-formed morphology prepared from a Prussian blue analogue template," Dalton Trans., vol. 44, no. 31, pp. 14034-14041, 2015.

[19] K. Shameli, M. B. Ahmad, A. Zamanian et al., "Green biosynthesis of silver nanoparticles using Curcuma longa tuber powder," International Journal of Nanomedicine, vol. 7, pp. 5603-5610, 2012.

[20] V. V. T. Padil and M. Černík, "Green synthesis of copper oxide nanoparticles using gum karaya as a biotemplate and their antibacterial application," International Journal of Nanomedicine, vol. 8, pp. 889-898, 2013.

[21] A. I. Lukman, B. Gong, C. E. Marjo, U. Roessner, and A. T. Harris, "Facile synthesis, stabilization, and anti-bacterial performance of discrete Ag nanoparticles using Medicago sativa seed exudates," Journal of Colloid and Interface Science, vol. 353, no. 2, pp. 433-444, 2011.

[22] J. G. Parsons, J. R. Peralta-Videa, and J. L. Gardea-Torresdey, "Chapter 21. Use of plants in biotechnology: synthesis of metal nanoparticles by inactivated plant tissues, plant extracts, and living plants," Developments in Environmental Science, vol. 5, pp. 463-485, 2007.

[23] J. H. Clark, "Green chemistry: challenges and opportunities," Green Chemistry, vol. 1, no. 1, pp. 1-8, 1999.

[24] J. Y. Song and B. S. Kim, "Rapid biological synthesis of silver nanoparticles using plant leaf extracts," Bioprocess and Biosystems Engineering, vol. 32, article 79, 2009.

[25] J. L. Gardea-Torresdey, J. G. Parsons, E. Gomez et al., "Formation and growth of Au nanoparticles inside live Alfalfa plants," Nano Letters, vol. 2, no. 4, pp. 397-401, 2002.

[26] J. L. Gardea-Torresdey, E. Gomez, J. R. Peralta-Videa, J. G. Parsons, H. Troiani, and M. Jose-Yacaman, "Alfalfa sprouts: a natural source for the synthesis of silver nanoparticles," Langmuir, vol. 19, no. 4, pp. 1357-1361, 2003. 
[27] S. Ahmed, Saifullah, M. Ahmad, B. L. Swami, and S. Ikram, "Green synthesis of silver nanoparticles using Azadirachta indica aqueous leaf extract," Journal of Radiation Research and Applied Sciences, vol. 9, no. 1, pp. 1-7, 2016.

[28] S. P. Chandran, M. Chaudhary, R. Pasricha, A. Ahmad, and M. Sastry, "Synthesis of gold nanotriangles and silver nanoparticles using Aloe vera plant extract," Biotechnology Progress, vol. 22, no. 2, pp. 577-579, 2006.

[29] J. Huang, Q. Li, D. Sun et al., "Biosynthesis of silver and gold nanoparticles by novel sundried Cinnamomum camphora leaf," Nanotechnology, vol. 18, no. 10, Article ID 105104, pp. 105-106, 2007.

[30] S. Li, Y. Shen, A. Xie et al., "Green synthesis of silver nanoparticles using Capsicum annuum L. extract," Green Chemistry, vol. 9, no. 8, pp. 852-858, 2007.

[31] A. E. Lamb, W. N. Anderson, and R. G. Haverkamp, "The induced accumulation of gold in the plants Brassica juncea, Berkheyacoddii and Chicory," Chemistry in New Zealand, vol. 9, pp. 34-36, 2001.

[32] S. S. Shankar, A. Ahmad, A. Rai, and M. Sastry, "Rapid synthesis of $\mathrm{Au}, \mathrm{Ag}$, and bimetallic $\mathrm{Au}$ core-Ag shell nanoparticles using Neem (Azadirachta indica) leaf broth," Journal of Colloid and Interface Science, vol. 275, no. 2, pp. 496-502, 2004.

[33] S. S. Shankar, A. Rai, B. Ankamwar, A. Singh, A. Ahmad, and M. Sastry, "Biological synthesis of triangular gold nanoprisms," Nature Materials, vol. 3, no. 7, pp. 482-488, 2004.

[34] P. C. Sharma, V. Bhatia, N. Bansal, and A. Sharma, "A review on Bael tree," Natural Product Radiance, vol. 6, pp. 171-178, 2007.

[35] P. S. Praba, V. S. Vasantha, J. Jeyasundari, and Y. B. A. Jacob, "Synthesis of plant-mediated silver nanoparticles using ficus microcarpa leaf extract and evaluation of their antibacterial activities," European Chemical Bulletin, vol. 4, no. 3, pp. 116-120, 2015.

[36] N. Krithiga, A. Rajalakshmi, and A. Jayachitra, "Green synthesis of silver nanoparticles using leaf extracts of Clitoria ternatea and Solanum nigrum and study of its antibacterial effect against common nosocomial pathogens," Journal of Nanoscience, vol. 2015, Article ID 928204, 8 pages, 2015.

[37] A. Miri, M. Sarani, M. R. Bazaz, and M. Darroudi, "Plantmediated biosynthesis of silver nanoparticles using Prosopis farcta extract and its antibacterial properties," Spectrochimica Acta Part A: Molecular and Biomolecular Spectroscopy, vol. 141, pp. 287-291, 2015.

[38] N. Muniyappan and N. S. Nagarajan, "Green synthesis of silver nanoparticles with Dalbergia spinosa leaves and their applications in biological and catalytic activities," Process Biochemistry, vol. 49, no. 6, pp. 1054-1061, 2014.

[39] P. Maity, D. Hansda, U. Bandyopadhyay, and D. K. Mishra, "Biological activities of crude extracts and chemical constituents of bael, Aegle marmelos (L.) Corr," Indian Journal of Experimental Biology, vol. 47, no. 11, pp. 849-861, 2009.

[40] K. B. Narayanan and N. Sakthivel, "Biological synthesis of metal nanoparticles by microbes," Advances in Colloid and Interface Science, vol. 156, no. 1-2, pp. 1-13, 2010.

[41] N. P. Yadav and C. S. Chanotia, "Phytochemical and pharmacological profile of leaves of aegle marmelos linn," Pharmacological Reviews, pp. 144-159, 2009.

[42] K. J. Rao and S. Paria, "Green synthesis of silver nanoparticles from aqueous Aegle marmelos leaf extract," Materials Research Bulletin, vol. 48, no. 2, pp. 628-634, 2013.
[43] K. J. Rao and S. Paria, "Aegle marmelos leaf extract and plant surfactants mediated green synthesis of $\mathrm{Au}$ and Ag nanoparticles by optimizing process parameters using Taguchi method," ACS Sustainable Chemistry \& Engineering, vol. 3, no. 3, pp. 483491, 2015.

[44] K. V. P. Kumar, O. S. N. Ghosh, G. Balakrishnan, P. Thirugnanasambantham, S. K. Raghavan, and A. K. Viswanath, "Green synthesis of zinc oxysulfide quantum dots using aegle marmelos fruit extract and their cytotoxicity in HeLa cells," RSC Advances, vol. 5, no. 22, pp. 16815-16820, 2015.

[45] J. Dolezal and V. Kourim, "Affinities of insoluble cyanoferrates of iron(III), cobalt(II), nickel(II), copper(II) and zinc(II) towards sodium, potassium, rubidium, caesium and ammonium," Radiochemical and Radioanalytical Letters, vol. 1, pp. 295-295, 1969.

[46] K. Chandra, D. Raj, and S. P. Puri, "Mössbauer studies of ferroand ferricyanide supercomplexes with 3d transition elements," The Journal of Chemical Physics, vol. 46, no. 4, pp. 1466-1468, 1967.

[47] N. Daneshvar, D. Salari, and A. R. Khataee, "Photocatalytic degradation of azo dye acid red 14 in water on $\mathrm{ZnO}$ as an alternative catalyst to $\mathrm{TiO}_{2}$," Journal of Photochemistry and Photobiology A: Chemistry, vol. 162, no. 2-3, pp. 317-322, 2004.

[48] A. D. Bokare, R. C. Chikate, C. V. Rode, and K. M. Paknikar, "Iron-nickel bimetallic nanoparticles for reductive degradation of azo dye Orange G in aqueous solution," Applied Catalysis B: Environmental, vol. 79, no. 3, pp. 270-278, 2008.

[49] D. Rajkumar, B. J. Song, and J. G. Kim, "Electrochemical degradation of Reactive Blue 19 in chloride medium for the treatment of textile dyeing wastewater with identification of intermediate compounds," Dyes and Pigments, vol. 72, no. 1, pp. $1-7,2007$.

[50] S. K. Kansal, M. Singh, and D. Sud, "Studies on photodegradation of two commercial dyes in aqueous phase using different photocatalysts," Journal of Hazardous Materials, vol. 141, no. 3, pp. 581-590, 2007.

[51] S. Viladkar, T. Alam, and Kamaluddin, "Adsorption of aromatic amines on metal ferrocyanides," Journal of Inorganic Biochemistry, vol. 53, no. 1, pp. 69-78, 1994.

[52] M. Cheng, W. Ma, J. Li et al., "Visible-light-assisted degradation of dye pollutants over $\mathrm{Fe}$ (III)-loaded resin in the presence of $\mathrm{H}_{2} \mathrm{O}_{2}$ at neutral $\mathrm{pH}$ values," Environmental Science \& Technology, vol. 38, no. 5, pp. 1569-1575, 2004. 

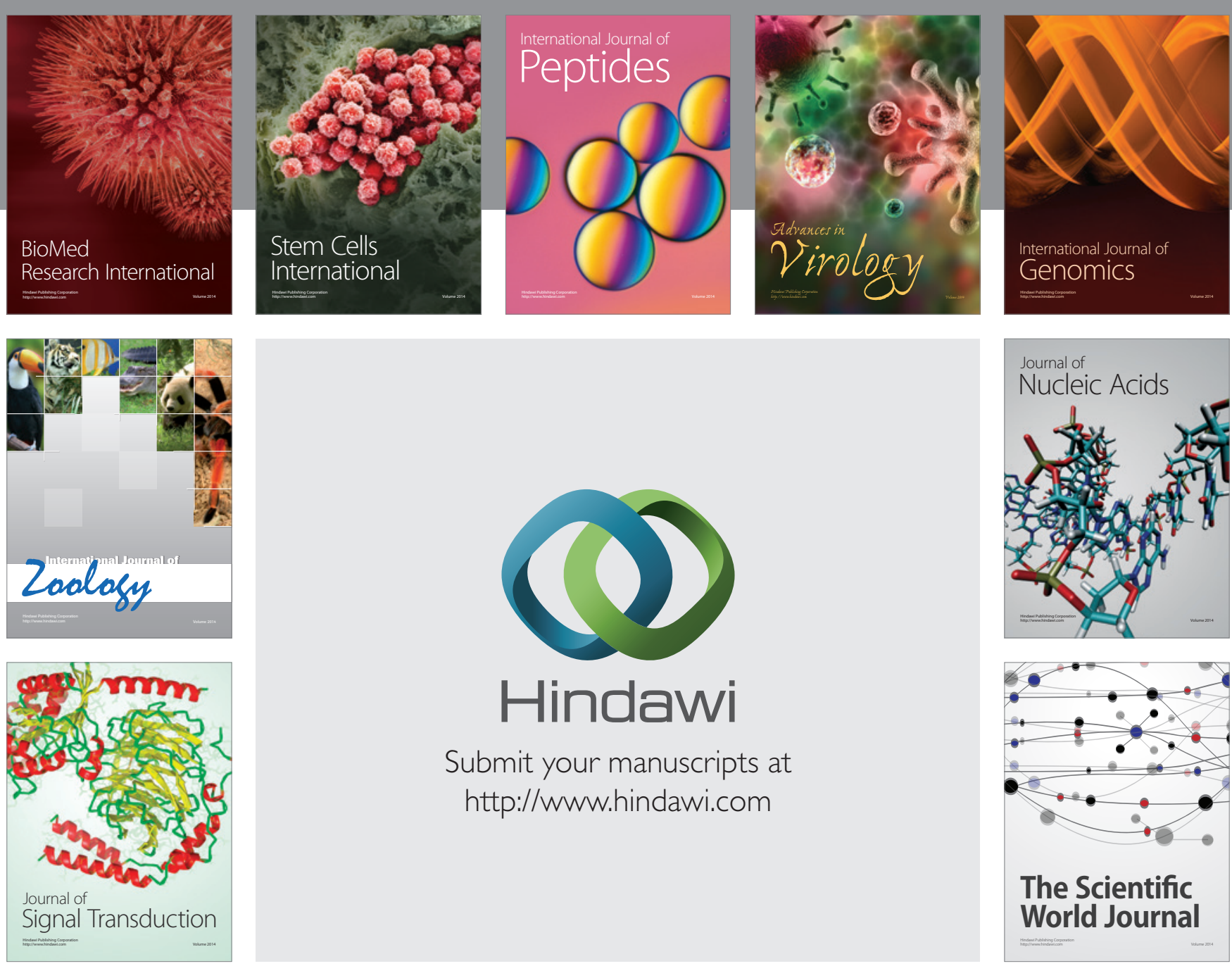

Submit your manuscripts at

http://www.hindawi.com
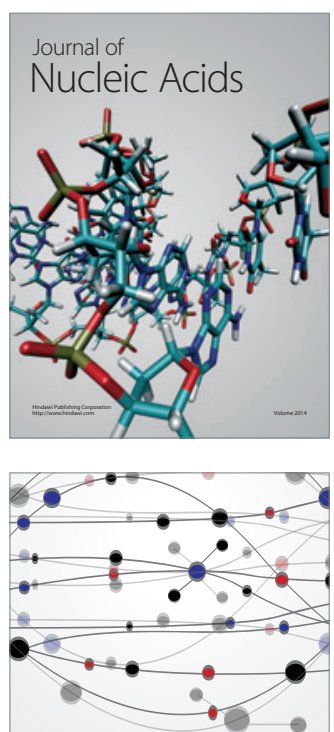

The Scientific World Journal
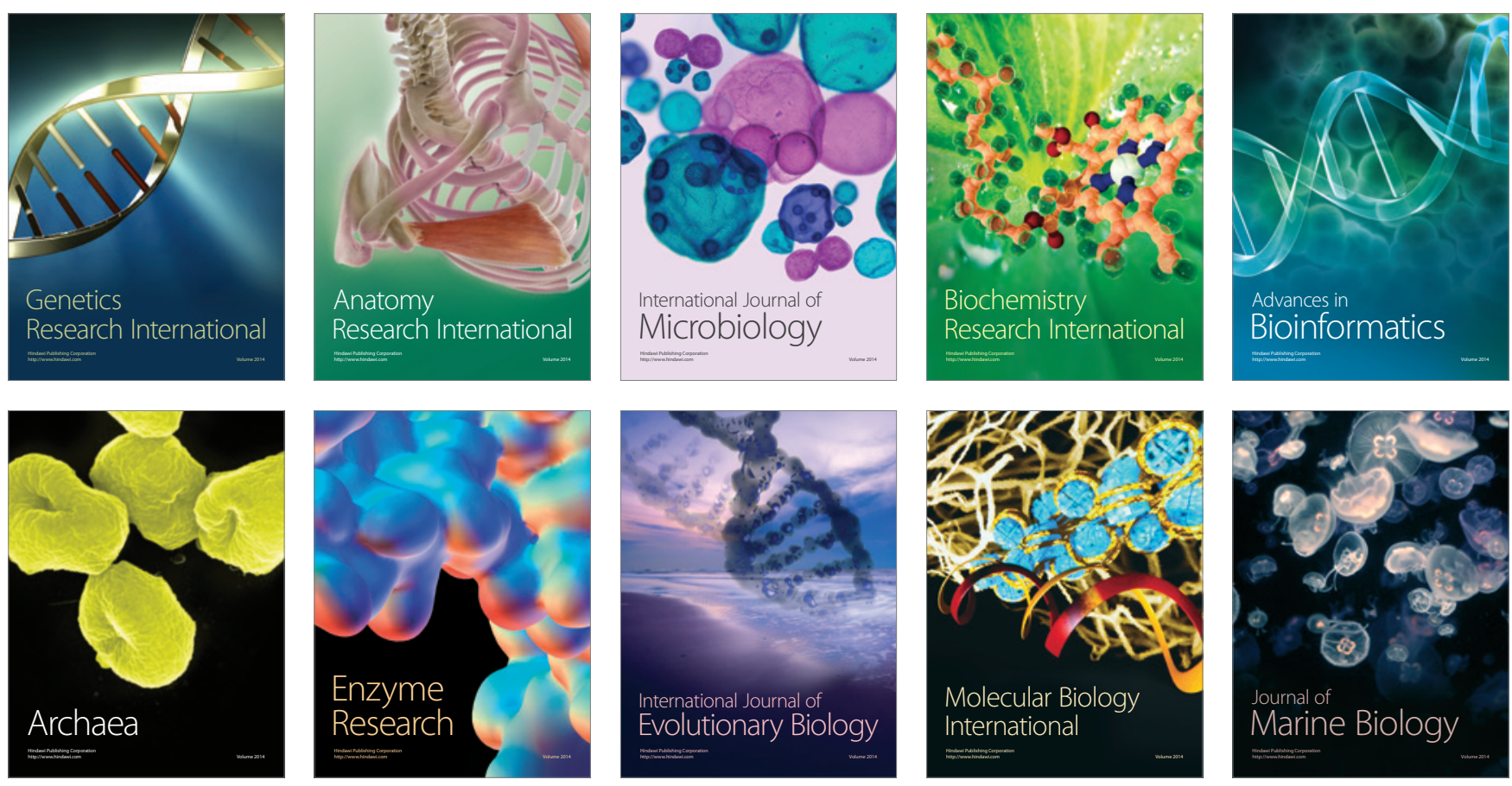